\title{
Hepatic sinusoidal ectasia in association with Hodgkin's disease
}

\author{
BARBARA J. BAIN* \\ M.R.C.Path., F.R.A.C.P. \\ SHiRley J. CoghlaN* \\ M.R.C.P. (Lond).
}

K. C. ChONG*

F.R.C.P.A.

SYDNEY J. ROBERTS $\dagger$
F.R.A.C.R., F.R.C.R.

\section{Departments of *Haematology and Morbid Anatomy, Princess Alexandra Hospital, and the †Queensland Radium Institute, Brisbane, Queensland, Australia}

\begin{abstract}
Summary
A patient developed abnormal liver function tests in association with hepatic sinusoidal ectasia concurrently with relapse of Hodgkin's disease. Tests returned to normal following successful chemotherapy for the Hodgkin's disease. Sinusoidal ectasia and the related condition, peliosis hepatis, should be recognized as rare non-infiltrative manifestations of Hodgkin's disease.
\end{abstract}

\section{Introduction}

Hodgkin's disease may be associated with a variety of pathological lesions in the liver other than lymphomatous infiltration; lesions include granulomas, cholestasis which may rarely progress to cirrhosis, amyloidosis, and portal tract accumulations of histiocytes, eosinophils, lymphocytes and granulocytes. The patient to be reported, and several previous reports, suggest that sinusoidal ectasia and peliosis hepatis should be recognized as non-infiltrative manifestations of Hodgkin's disease.

\section{Case report}

A 30-year-old man presented in January 1976 with three enlarged lymph nodes in the left anterior triangle of the neck. Biopsy showed mixed cellularity Hodgkin's disease. Detailed investigations including a staging laparotomy with splenectomy gave no evidence of disease elsewhere and he was therefore staged as IA. Liver function tests (bilirubin, alkaline phosphatase, and aspartate aminotransferase) were normal. Wedge and needle-liver biopsies at laparotomy showed only a slight increase in chronic inflammatory cells in the portal tracts. Radical radiotherapy to a mantle field was given $(3500 \mathrm{rad}$ in 20 fractions over 4 weeks with boosting to 4000 rad over the involved nodes).

Requests for reprints: Dr B.J. Bain, St Mary's Hospital Medical School, London W2 1PG
Follow-up was uneventful until May 1977, when routine liver function test showed the alkaline $\stackrel{9}{\checkmark}$ phosphatase to be $244 \mathrm{u}$./1 (normal 20-85). The . patient felt well and had no abnormal physical $\vec{\infty}$ findings. In June, the alkaline phosphatase was $207 \mathrm{u} . / \mathrm{l}$, 5-nucleotidase (5-NT) $18 \mathrm{u} . / 1$ (normal $2-11)$ and $\gamma$-glutamyl transpeptidase $(\gamma$-GT) 173 u./1 (normal 5-65). Bilirubin and aspartate aminotransferase remained normal. In September the patient continued to feel well with no abnormal physical findings and a normal chest X-ray, bug admitted to a $12 \mathrm{~kg}$ weight-loss in the preceding twelve months. Further investigations showe haemoglobin $9.5 \mathrm{~g} / \mathrm{dl}$, erythrocyte sedimentationt rate $84 \mathrm{~mm} / \mathrm{hr}$, platelet count $1098 \times 10^{9} / 1$; alkaline phosphatase $291 \mathrm{u} . / \mathrm{l} ; 5-\mathrm{NT} 398 \mathrm{u} . / \mathrm{l} ; \quad \gamma$-GT 260 u./1 and albumin $37 \mathrm{~g} / \mathrm{dl}$ (normal 35-45); $\alpha_{2^{-}}$and $\gamma$-globulins were elevated and the iron binding capacity was reduced.

It was considered likely that the Hodgkin's disease had recurred. Lymphangiography showed a diffuse enlargement of many para-aortic and external iliac nodes with a bubbly texture and large filling defects. A percutaneous liver biopsy showed a slight increase in portal tract lymphocytes; there were also some clusters of blood spaces, the significance of which was not appreciated. It was considered important for choice of therapy to discover if the patient had liver infiltration, or alternatively nodal disease only, with reactive changes in the liver. The patient was therefore submitted to a second staging laparotomy in October 1977. Nodal biopsies confirmed recurrent mixed cellularity Hodgkin's N disease. At surgery, the liver was noted to be enlarged and vascular with a dark mottled appearance. A wedge biopsy and two needle biopsies were taken.

The wedge biopsy showed marked sinusoidal ectasia with the lining endothelial cells being benign in appearance. Some dilated blood spaces lacked an endothelial lining (Fig. 1). The changes 


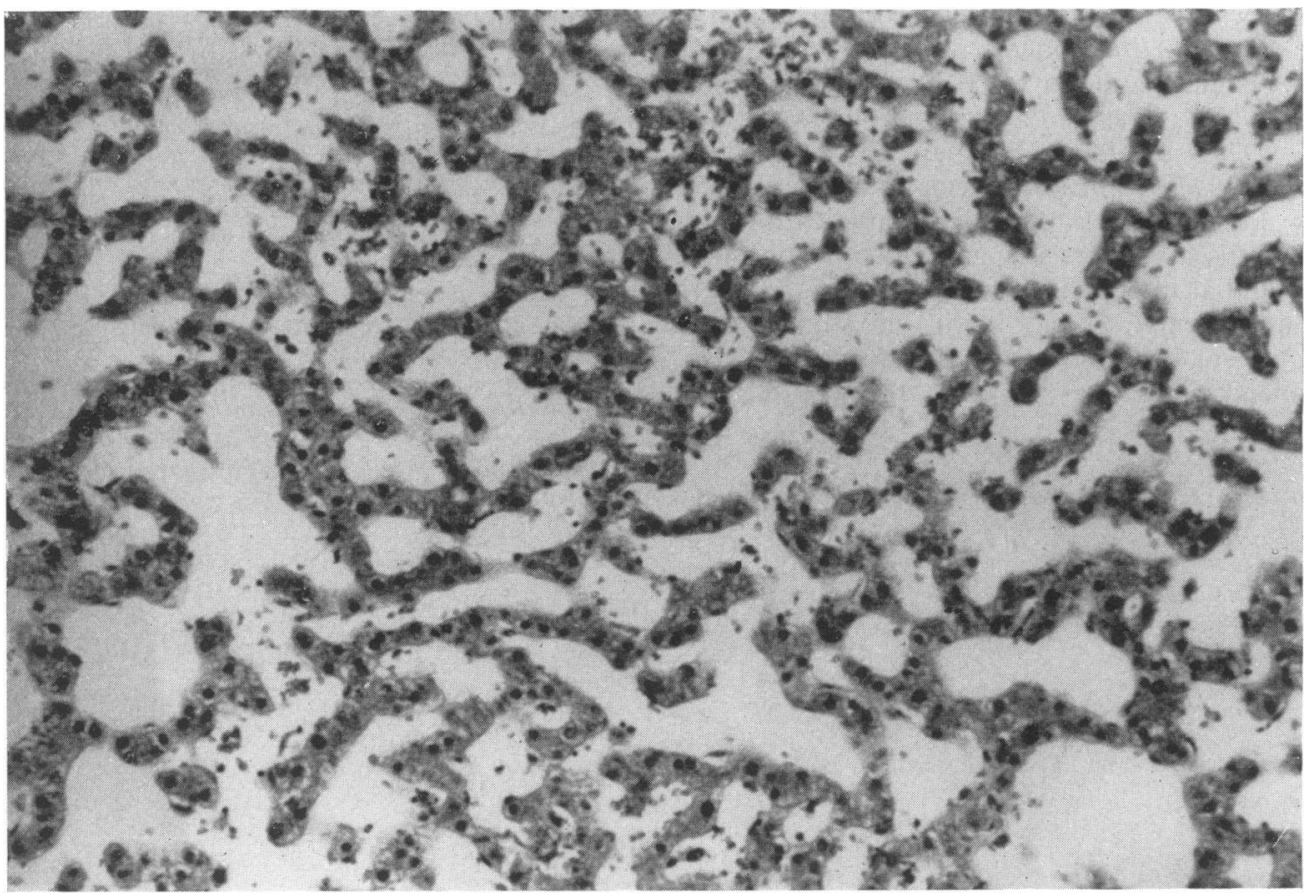

FIG. 1. Wedge biopsy of liver showing hepatic sinusoidal ectasia $(\mathrm{HE}, \times 160)$.

were most marked in the subcapsular zone but were also present deeper in the liver. The dilated sinusoids had no constant relationship with central veins and portal tracts. Central veins were mildly engorged with no evidence of perivenous fibrosis. Portal tracts were normal except for a few lymphocytes and eosinophils in some tracts. Liver cells were swollen in some areas and granular brown pigment was seen in some Kupffer cells. There were no granulomas, nor any evidence of Hodgkin's disease. The two needle biopsies had the same appearance although blood spaces were less prominent.

Postoperatively the patient was given radical radiotherapy $(3500 \mathrm{rad})$ to an inverted $Y$ field, followed by six courses of combination chemotherapy (MOPP regime). By February 1978, liver function tests had returned to normal and subsequently have remained so. The patient has been followed-up until June 1981 and has had no clinical, radiological or laboratory evidence of further recurrence. At no time did he take any androgenic or anabolic steroids.

\section{Discussion}

A young man with Hodgkin's disease developed abnormal liver function tests associated with sinusoidal ectasia concurrently with the relapse of his disease. There had been no evidence of dilatation of sinusoids at staging laparotomy 15 months earlier. Following successful retreatment of his Hodgkin's disease the liver function tests returned to normal.

Sinusoidal dilatation has been previously noted in patients with Hodgkin's disease (Bruguera et al., 1978) being found in 6 of 16 hepatic biopsies, only one of which showed lymphomatous infiltration. The patient now reported demonstrates that sinusoidal ectasia may be associated with marked abnormality of liver function tests. The return of such tests to normal with successful treatment of the Hodgkin's disease suggests that the sinusoidal ectasia may have regressed with remission of the primary disease.

Sinusoidal ectasia may be the initial stage, or may represent a minor degree, of peliosis hepatis. Sinusoidal ectasia may be seen in livers showing the phlebiectatic form of peliosis hepatis and both lesions are seen following the administration of anabolic and androgenic steroids, and in association with malignant disease and tuberculosis. The macroscopic appearance of the liver of the present patient suggests that he may have had early phlebiectatic peliosis hepatis in addition to marked sinusoidal dilatation but no definite blood cysts were seen in the biopsy.

There have been seven patients reported with 
peliosis hepatis in association with Hodgkin's disease. Three of the patients were taking anabolic steroids (Bagheri and Boyer, 1974; McDonald and Speicher, 1978; Taxy, 1978) but four were not (Taxy, 1978; Duffaud-Thierman et al., 1977; Weicksel, 1957). Sinusoidal ectasia and peliosis hepatis are rare, non-infiltrative complications of Hodgkin's disease. Peliosis hepatis may be responsible for the initial presentation of Hodgkin's disease (Duffaud-Thierman et al., 1977) and similarly, as in this patient, sinusoidal ectasia may produce the first evidence of relapse.

\section{References}

BAgheri, S.A. \& Boyer, J.L. (1974) Peliosis hepatis as-

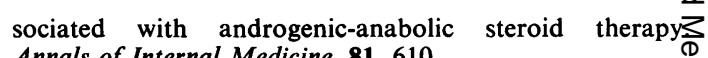
Annals of Internal Medicine, 81, 610.

Bruguera, M., Aranguibel, F., Ros, E. \& Rodes, $\mathfrak{t}$ (1978) Incidence and clinical significance of sinusoidal. dilation in liver biopsies. Gastroenterology, 75, 474.

Duffaud-Thierman, D., Hecht, Y., Callard, P., DE St Maur, P., Levy, V.G. \& Smadja, M. (1977) La péliose hépatique. Tableau clinique et para-clinique à propos dê. six observations d'étiologie inhabituelle. Médecine es Chirurgie Digestives, 6, 519.

McDonald, E.C. \& Speicher, C.E. (1978) Peliosis hepatis associated with oxymethalone. Journal of the American Medical Association, 240, 243.

TAXY, J.B. (1978) Peliosis; a morphologic curiosity becomes an iatrogenic problem. Human Pathology, 10, 331.

Weicksel, A. (1957) Zur Frage der Peliosis innerer Organe Zentralblatt für allgemeine Pathologie und pathologischల్ Anatomie, 96, 113. 